donbt the cause of the paralysis, as the latter is connected with the thalamus, and what is known as the meso-cephalon, the shiverings and tremblings in this disease, and delirium tremens, depending on irritation of the arachnoid. The case has evidently a very extended bearing on the subject of phlebitis and pyæmia, showing how this disease may occur under circumstances not at all to be suspected. A case, apparently of traumatic fever, under the care of Mr. Lloyd, we watched also, last month, at Bartholomew's; which, as feared, ended in purnlent deposits in various organs. More than one fatal case lately, at the London Hospital, has also commenced in this insidious manner; but we should be very slow, indeed, to believe that any possible amount of skill or prevision could prevent such results. In this point of view, indeed, we deem Dr. Addison's case peculiarly instructive.

\section{POST-MORTEM APPEARANCES IN THE CASE OF DEATH FROM} CHLOROFORM.

(Under the care of Mr. BIRketT.)

As very unusual interest attaches to deaths from chloroform, referred to elsewhere, we give the post-mortem appearances, kindly furnished us by Mr. Birkett.

Hannah B-_, aged fifty-six, was admitted into Guy's Hospital on the 15th of November, 1854, under the care of Mr. Birkett. She described herself as in good health, but presented a most cachectic appearance, edentulous, and appeared perhaps ten years older than the age assigned. She complained of chronic ulceration of her left leg for the last two years, the ulceration appearing to surround the leg at about the junction of the middle and lower thirds. Two months before admission into Guy's, the ulcer assumed a sprouting, fungating aspect, became very painful, and during the last month it bled frequently and profusely. In the left groin there was an enlarged gland. Various means having been incffectually employed to destroy the cancer, amputation below the knee was proposed and agreed to by the patient. The woman had a little wine-and-water, according to a recent suggestion, before taking the chloroform. And here we may remark that the fatality of chloroform would seem to be greater at some hospitals than at others, while in Edinburgh it has been said no deaths have occurred.

At one o'clock P.M. on the 5th, she was brought into the operating theatre, and chloroform administered in the usual method at Guy's, on folds of lint. During the inhalation of the vapour, the tourniquet was adjusted to the femoral artery; it was screwed tightly for a few seconds, to ascertain if it com manded the artery, but, we observed, was immediately after slackened. The inhalation had been continued a minute or two, when considerable muscular movements, so frequent in this stage, took place; these were followed by rigidity. Mr. Birkett was about to operate, when Mr. Callaway, in the capacity of assistant at the operation, called attention to the only remarkable circumstances noted, the pulse stopped at the wrist, swelling of the veins of the neck, expirations performed also with considerable sufflation of the cheeks and sudden opening of the lips. The poor woman was less than five minutes under the action of the vapour; there had been no vomiting, and particular care was taken there should be no solid food in the stomach. We give these particulars, as we think the working out the problem of the cause of death after chloroform inhalation one of the most interesting perhaps which can engage the profession at present.

The post-mortem, conducted with great care and skill by Dr. Wilkes, revealed a very large amount of organic disease. The external appearance was that of a woman at least ten years older than her real age; hair quite grey; arcus senilis of the eyes; body spare, the skin presenting the smooth, yellow appearance too often indicative of senile fatty degeneration. A chronic ulcer, of very bad kind, existed on the right leg, and on the left a large fungating mass. There was the usual amount of blood in the brain; the membrancs healthy; the subarachnoid fluid greatly increased in quantity, due perhaps to wasting of the brain; the convolutions were shrunken, but healthy; the ventricles contained an increased amount of serum; one choroid plexus vesicular; the cerebral arteries contained atheromatous matter and bony patches; the medulla oblongata did not exhibit any morbid appearance. The larynx, trachea, and pleuræ were all healthy; the lungs were very much congested with blood, bleeding very freely when cut. The heart was of usual size; all its cavities empty; the endocardial membrane of the left ventricle had various patches and streaks of fibroid degeneration; the heart-fibres presented zigzag lines of fatty degeneration; they were slightly granular, and contained fat, as seen under the microscope; this was more in the right ventricle than in the left; the fleshy columns of the mitral valve were also diseased in the same way. The liver was also diseased. On examining the ulcer on the leg, it was found to be full of cancer-cells, large and nucleated.

\section{KING'S COLLEGE HOSPITAL.}

\section{THE CACSES OF SCURYY IN ARMIES.}

(Under the care of Dr. BuDd.)

A CASE of scurvy in this hospital has given Dr. Budd an opportunity to make some practical bed-side remarks on this disease, which he feared will attack our English army in the spring if timely precaution be not taken to avert such an evil. The causes of scurvy, or at least the causes popularly coneeived to produce scurvy, are singular instances of bad reasoning-the post hoc put for the propter hoc. At one time, and not long ago, it was thought it was the cold of winter produced this disease; then on board ship it was believed it was salt meat, as it occurs after long voyages, and chiefly in spring or in the end of winter. These are not the carnses, but they run parallel with the cause-namely, want of vegetable food. This Dr. Budd believes to be the great, if not the one only, specific cause of scurvy. Scurvy is often mistaken for purpura; but the latter, we need hardly remark, is more of the nature of a hæemorrhage, and often met with where there is plenty of vegetable food. In scurvy the gums are soft and swelled, spongy, and bleeding readily. It is a disease marked by excessive delility, but readily cured by lemon-juice, fresh vegetables, or fruits; the latter supplying something which bread or meat or other kinds of food fail to supply to the blood. The farinaceous seeds, wheat, barley, oats, rye, are found to be deficient in those principles; while potatoes, according to Vauquelin and Erichoff, though paradoxical it may appear, possess the same acid as lemons. The Turkish army, according to some work quoted by Dr. Budd, suffered severely from scurvy last spring under Omar Pacha. Dr. Budd rather gravely remarked, without premeditation, they might prove with scurvy under Lord Raglan, which raised considerable laughter in the class, always attentive to this excellent lecturer's addresses-an interruption he turned to account by remarking that we, too, might have our own poor troops destroyed by it if timely care were not taken. The class seemed to think the Turks our defenders, rather deserved scurvy for running away so often---a feeling too sad when applied to our own troops; but fixing the matter painfully in the recollection, as, by the last accounts from the seat of war, scurvy was already making its appearance.

\section{THE YALUE OF THE BICROSCOPE IN CANCER}

(Under the care of Mr. Partridge.)

Mr. Partridge removed a breast some days ago, or rather a scirrhous mass from the region of the mammary gland-an operation in itself of little moment, but a subject which has caused considerable speculation, and gained no little importance of late in clinical conversation in hospitals, from the recent singular statement of Velpeau, that, in spite of our microscopes and micrology, he has cured twenty cases of cancer. Some of our London surgeons agree with the Paris school, or rather the section headed by this eminent writer, in believing that there is no specific cell characteristic of malignant growth, and the so-called specific cells are too often risiblo in growths apparently benignant. Mandl, Virchow, Bennet, and $\mathrm{Mr}$. Paget, have, it is true, brought their learning to bear against the plain common sense of Velpeau; but it seems the latter is right, and on repeating his observations in London, it is found these so-called malignant cells are very often secondary products or formations, even at best, sometimes of no very marked charncter. There has been seldom so much wit and learning brought into a discussion as in this on the value of the microscope in the diagnosis of malignant growths. We should be sorry to find the microscope lose any of its prestige as almost an additional sense conferred on the practical man. Witness only the singular rerelations of adulterations of food and medicine in the pages of the "Analytical Sanitary Commission" of The LinceT; or in the works of Peyer or Pereira; yet we cannot help believing that in hospitals, more especially in the practice of older men, like Mr. Lawrence, Mr. Green, Ar. Luke, \&c., there has been for some time growing up considerable doubt, not as to the value of the microscope, for these gentlemen are rather amiably ignorant of its value, but as to the regularity of return or repullulative character of what are otherwise deemed malignant 